\title{
Development of Thermal Insulation Plasters for Insulating and Sanitation of Building Constructions
}

\author{
J. Zach, R. Hela, M. Sedlmajer, and J. Hroudova
}

\begin{abstract}
Work on thermal insulation of outer structures of buildings is an issue that is often closely associated with moisture sanitation and recovery / sanitation of the damaged layers of outer surface conditioning. In the case of historic buildings or in the case of sanitation aimed at a part of the outer structure only, it is not possible to apply conventional external thermal contact insulation systems (ETICS). Regarding these cases, there is an effective way consisting in application of thermal insulation plasters with high porosity and regulated capillary properties which ensure improvement of thermal and technical properties of the structure, its diffusion openness towards the outside environment. In case of appropriate conditioning of the capillary properties, it can prevent liquid moisture and salt from penetrating toward the outer surface of the structure.

The paper describes the results of research that is oriented toward the development of ultra-light thermal insulation plasters on silicate base, which can be due to high porosity and good stability at elevated humidity used for applications with higher moisture load too.
\end{abstract}

Index Terms-Historical objects, sanitation, thermal insulating plasters, thermal technical properties.

\section{INTRODUCTION}

During reconstruction work and sanitation of outer surfaces of the building structures, there is an ever-increasing demand on thermal-insulating properties of materials used, especially in the cases where the reconstruction covers the buildings with high moisture. In these cases, it is especially necessary to use materials with high open porosity, low value of thermal conductivity and good mechanical properties.

This paper describes the results of research aimed to development of lightweight thermal insulating plasters with light aggregate based on expanded obsidian and with using alternative raw materials, presented by meta-kaolin and finely ground fly-ash of power stations.

Before it was found that the use of meta-kaolin, as a substitute for cement in lightweight thermal-insulating plasters based on lightweight aggregate and lime hydrate, can help to achieve significant improvement in mechanical properties, while maintaining very good thermal-insulating properties too. However, the disadvantage of metakaolin lies

Manuscript received February17, 2013; revised May 20, 2013. This work was supported in part by the financial support of the project MPO FR-TI1/253 and project n. 7AMB12AT009 "Study of behavior of advanced silicate materials used for thermal insulation and sanitation of building constructions" from program AKTION 2012/13.

The authors are with the Brno University of Technology, Faculty of Civil Engineering, Veveri 95, 60200 Brno, Czech Republic (e-mail: zach.j@fce.vutbr.cz, hela.r@fce.vutbr.cz, sedlmajer.m@fce.vutbr.cz, hroudova.j@fce.vutbr.cz). in very high price which is significantly higher than the price of cement. Therefore, we were trying to replace the meta-kaolin with another hydraulic or latent hydraulic binding material. As suitable substitution, we chose finely ground fly-ash of power-stations, the fly-ash which, in combination with lime hydrate, shows comparable properties as those of metakaolin. However, the purchase price is in comparison with metakaolin substantially lower. [1]

When working on development of plasters intended for sanitation and thermal insulation of buildings, there was a major effort to achieve the best possible ratio of thermal insulation and mechanical properties. In terms of using these materials in practice, there have been established the basic requirements related to the above-mentioned key parameters of materials developed, namely:

1) Requirement for the maximum value of thermal conductivity in dry state $\lambda_{10, \text { dry, max }}=0,08 W \cdot \mathrm{m}^{-1} \cdot \mathrm{K}^{-1}$,

2) Requirement for the minimum compressive strength $f_{c, \text { min }}=0,5 \mathrm{~N} \cdot \mathrm{mm}^{-2}$.

It was further required that the density of materials being developed was in the range of $250-500 \mathrm{~kg} \cdot \mathrm{m}^{-3}$ and that the materials achieved a high value of open porosity. These parameters should predetermine the use of materials in the field of thermal insulations of building structures associated with sanitation of moisture (this is not about classic sanitation plasters according to the WTA directive). [2]

\section{Test SAmples and Production of Test SAmples}

When working on the development of thermal-insulating plasters using meta-kaolin and finely ground fly-ash of power stations, there were 6 test recipes suggested in total. The basis of all the test mixtures consisted in lightweight porous aggregate based on expanded obsidian and also the lime hydrate. The amount of hydraulic / latent hydraulic binding material was uniformly chosen as the amount of 50 $\mathrm{kg}$ per $1 \mathrm{~m}^{3}$ of the mixture. [3]

Individual test recipes were designed in order to monitor the effect of type and amount of used binding material on the resulting property of developed materials in the hardened condition. Water was dosed individually for each mixture in order to achieve consistency of spillage according to EN 1015-3 in the range of 140 to $150 \mathrm{~mm}$. The composition of the individual recipes, including the doses of partial components, is shown in Table I, mentioning the composition of mixtures for $1 \mathrm{~m}^{3}$. In addition, there are also all the raw materials used for production of each test mixtures. [4]

Production of test samples for determination of monitored parameters was carried out with the mixer of Filamos M50 fitted with the function of forced circulation. The total 
volume of the test mixture was chosen in such ways that it was optimal to the type of mixer, the volume was 15 litres. In all the cases there was carried out determination of the properties of fresh mortar mixture, immediately after the mixing procedure.

TABLE I: OVERVIEW OF COMPOSITION OF TEST SAMPLES FOR $1 \mathrm{M}^{3}$

\begin{tabular}{lccccccc}
\hline \multicolumn{1}{c}{ Component } & & \multicolumn{7}{c}{ Recipe } \\
& & $\mathbf{1}$ & $\mathbf{2}$ & $\mathbf{3}$ & $\mathbf{4}$ & $\mathbf{5}$ & $\mathbf{6}$ \\
$\begin{array}{l}\text { Lightweight porous } \\
\text { aggregate }\end{array}$ & {$[\mathrm{kg}]$} & 97,4 & 97,4 & 97,4 & 97,4 & 97,4 & 97,4 \\
Lime hydrate & {$[\mathrm{kg}]$} & 150 & 150 & 150 & 150 & 150 & 150 \\
Cement & {$[\mathrm{kg}]$} & - & - & - & - & - & 50 \\
Meta-kaolin & {$[\mathrm{kg}]$} & - & 12,5 & 37,5 & 50 & 25 & - \\
Fly-ash & {$[\mathrm{kg}]$} & 50 & 37,5 & 12,5 & - & 25 & - \\
Methylcellulose & {$[\mathrm{kg}]$} & 0,9 & 0,9 & 0,9 & 0,9 & 0,9 & 0,9 \\
Air agent (Tylovis) & {$[\mathrm{kg}]$} & 0,75 & 0,75 & 0,75 & 0,75 & 0,75 & 0,75 \\
Water & {$[\mathrm{kg}]$} & 373 & 353 & 360 & 425 & 375 & 330 \\
\hline \hline
\end{tabular}

The test mixtures were used for preparation of test formations of the following shapes:

1) Block: $40 \times 40 \times 160 \mathrm{~mm}$ - for determining the mechanical properties, density, coefficient of thermal conductivity and coefficient of capillary absorption;

2) Board: $300 \times 300 \times 50 \mathrm{~mm}$ - for determining the coefficient of thermal conductivity in steady condition.

\section{RESUlTS OF THE MEASUREMENT}

The physical and rheological properties in fresh condition performed on the test samples were determined:

1) Determination of density according to EN 1015-6 [5],

2) Determination of rheological properties (spillage) according to EN 1015-3 [4].

The measurement results are shown in the following table II:

TABLE II: Properties of TeSting Plasters in the Fresh StATE [3], [4]

\begin{tabular}{cccc}
\hline \hline Recipie & $\begin{array}{c}\text { Addition of water } \\
{\left[\mathrm{kg} \cdot \mathrm{m}^{-3}\right]}\end{array}$ & $\begin{array}{c}\text { Flow value } \\
{[\mathrm{mm}]}\end{array}$ & $\begin{array}{c}\text { Density } \\
{\left[\mathrm{kg} \cdot \mathrm{m}^{-3}\right]}\end{array}$ \\
\hline 1 & 373 & 140 & 859 \\
2 & 353 & 140 & 820 \\
3 & 360 & 140 & 771 \\
4 & 425 & 140 & 810 \\
5 & 375 & 140 & 700 \\
6 & 330 & 140 & 820 \\
\hline \hline
\end{tabular}

The values listed in Table II show that (due to higher value of specific surface of meta-kaolin) it is necessary, in the case of mixture No. 4 with meta-kaolin, to use a higher amount of mixture water in order to achieve the same consistency like in other mixtures in which cement, fly-ash or combination of ash and meta-kaolin were used.

The physical and mechanical properties determination in the hardened condition was also carried. These were:

1) Determination of density according to EN 1015-10 [6],

2) Determination of compressive strength and tensile strength in bending according to EN 1015-11 [7],

3) Determination of the coefficient of capillary water absorption according to EN 1015-18 [8],
4) Determination of thermal conductivity was performed in dry condition at medium temperature $+10^{\circ} \mathrm{C}$ and within the temperature gradient of $10 \mathrm{~K}$, according to ISO 8301 . [9], [10]

The results of measurements and tests carried out on the test samples in hardened condition are listed in Table III.

TABLE III: Properties OF TESTING PLASTERS IN THE HARDENED CONDITION

\begin{tabular}{|c|c|c|c|c|c|}
\hline$\stackrel{\mathscr{2}}{\mathscr{C}}$ & Density & $\begin{array}{c}\text { Thermal } \\
\text { conductivity }\end{array}$ & $\begin{array}{c}\text { Compressive } \\
\text { strength }\end{array}$ & $\begin{array}{c}\text { Tensile } \\
\text { strength }\end{array}$ & $\begin{array}{c}\text { Coefficient of } \\
\text { capillary } \\
\text { water } \\
\text { absorption }\end{array}$ \\
\hline & {$\left[\mathrm{kg} \cdot \mathrm{m}^{-3}\right]$} & {$\left[\mathrm{W} \cdot \mathrm{m}^{-1} \cdot \mathrm{K}^{-1}\right]$} & {$\left[\right.$ N.mm $\left.{ }^{-2}\right]$} & {$\left[\mathrm{N} . \mathrm{mm}^{-2}\right]$} & {$\left[\mathrm{kg} . \mathrm{m}^{-2}\right]$} \\
\hline 1 & 427 & 0,0879 & 0,54 & 0,94 & 0,02604 \\
\hline 2 & 391 & 0,0848 & 0,47 & 0,85 & 0,02955 \\
\hline 3 & 358 & 0,0750 & 0,52 & 1,10 & 0,03068 \\
\hline 4 & 369 & 0,0883 & 0,34 & 0,80 & 0,01903 \\
\hline 5 & 334 & 0,0824 & 0,24 & 0,56 & 0,02392 \\
\hline 6 & 406 & 0,0921 & 0,31 & 0,37 & 0,03117 \\
\hline
\end{tabular}

As is evident from the measured values, the test mixtures showed significantly different mechanical properties at the same quantity of hydraulic / latently hydraulic binding materials. The best properties were shown in the sample in which meta-kaolin and fly-ash were used in the proportion of 75:25. The worst properties were shown in sample No. 6 containing the addition of Portland cement.

The measured values were evaluated. There was also verification of relations of thermal insulation properties towards density and the amount of fractions of individual types of binders. There was a weak correlation between the density and thermal conductivity demonstrated (correlation coefficient 0.62), whereas the value of the thermal conductivity were going up together with the increasing volume weight in the test mixtures, graph 1.

Furthermore, there was the verification of the dependence of compressive strength on the volume weight after 28 days. Chart 2 also reflects the dependence of compressive strength on the amount of binding material (separately for each type of binding materials). However, in this case there was no correlation demonstrated between these properties.

To compare the properties of each recipe, we chose the ratio of thermal insulation and mechanical properties of $c_{f c / \lambda}\left[s \cdot K \cdot \mathrm{mm}^{-2}\right]$. The calculated values of the ratio of mechanical and thermal insulation properties are listed in Table IV.

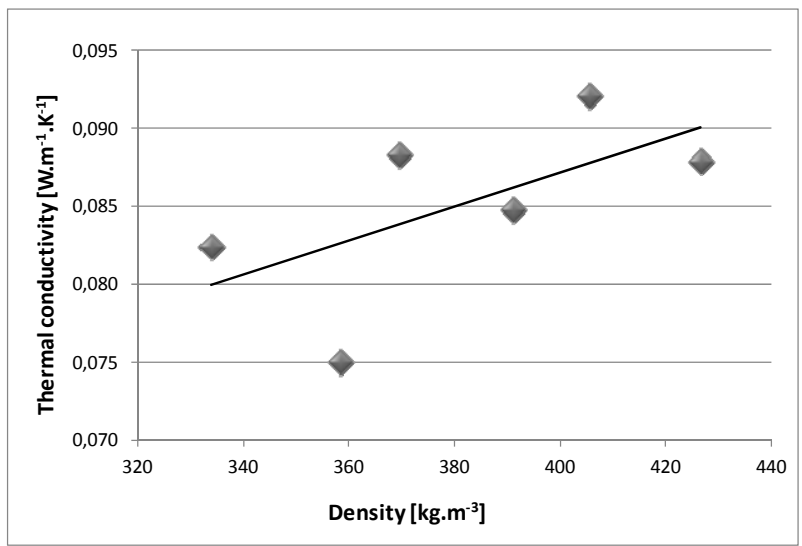

Fig. 1. Dependence of thermal conductivity on the density (in dry condition) 


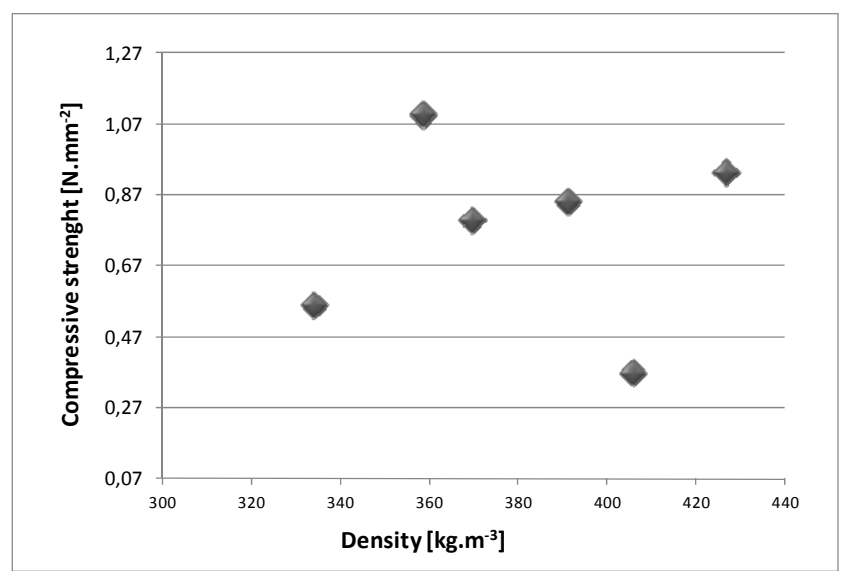

Fig. 2. Dependence of compressive strength on density

TABLE IV: Properties OF Testing Plastem in Freshened CONDITION

\begin{tabular}{l|llllll}
\hline Recipe & 1 & 2 & 3 & 4 & 5 & 6 \\
$\mathbf{c}_{\mathrm{fc} / \lambda}\left[\mathrm{s} \cdot \mathrm{K} \cdot \mathrm{mm}^{-2}\right]$ & 10,7 & 10,1 & $\mathbf{1 4 , 6}$ & 9,1 & 6,8 & 4,0 \\
\hline
\end{tabular}

In terms of thermal insulation and mechanical properties, the recipe No. 3 appears to be the best. This is the recipe in which both metakaolin and fly-ash were used at the ratio of $75: 25$.

\section{CONCLUSION}

It was found on the basis of the measurements that lightweight plaster mixtures which are based on lightweight aggregate of obsidian and lime hydrate show a very good ratio of thermal insulating and mechanical properties, especially if metakaolin or fly-ash from power stations are used as the binding material (or a combination of both).

In the case of using fly-ash from power stations, it was proved that fly-ash is a suitable alternative substitution for metakaolin, whereas the partial substitution of meta-kaolin for fly-ash in the ratio of 75:25 appears as the best solution, on the basis of the measurements.

In conclusion, it can be said that the developed materials show very good utility characteristics that determine their use in the field of sanitation of historic buildings. In this case, there were no internally hydrophobic materials developed, which is evident from the measured values of the coefficient of capillary absorption too (see Table III). If the plasters should be used as the ones for sanitation purposes, according to WTA specification, it would be necessary to reduce the capillary activity of the plasters by using appropriate hydrophobizers and higher amount of binding material in order to achieve the desired compressive strength of 1.5 N.mm ${ }^{-2}$.

Due to the high, open porosity and low volume weight, the developed materials have even without any additional treatment significant potential in the field of sanitation and thermal insulation of building structures in areas where the constructions have lower moisture load.

\section{ACKNOWLEDGMENT}

This paper was elaborated with the financial support of the project MPO FR-TI1/253 and project n. 7AMB12AT009 "Study of behavior of advanced silicate materials used for thermal insulation and sanitation of building constructions" from program AKTION 2012/13.

\section{REFERENCES}

[1] J. Zach, R. Hela, J. Hroudová, and M. Sedlmajer, "Utilization of Lightweight Aggregate from Expanded Obsidian for Advanced Thermal Insulating Plasters Production," Advanced Materials Research, 2011, pp. 1199 - 1203.

[2] R. Hela, J. Zach, and M. Sedlmajer, "The development of thermal insulating plasters for the insulation of historical buildings," in Proc. of the 3nd International Conference on Renewable Energy Sources and Energy Efficiency. 1. Cyprus, Ektoras Charalambides. 2011. pp. 398 - 402.

[3] Bulk sampling of mortars and preparation of test mortars, EN 1015-2 Methods of test for mortar for masonry.

[4] Determination of consistence of fresh mortar (by flow table), EN 1015-3 Methods of test for mortar for masonry.

[5] Determination of bulk density of fresh mortar, EN 1015-6 Methods of test for mortar for masonry.

[6] Determination of dry bulk density of hardened mortar, EN 1015-10 Methods of test for mortar for masonry.

[7] Determination of flexural and compressive strength of hardened mortar, EN 1015-11 Methods of test for mortar for masonry.

[8] Determination of water absorption coefficient due to capillary action of hardened mortar, EN 1015-18 Methods of test for mortar for masonry.

[9] ČSN 727012 Determination of Steady State Thermal Conductivity of Materials, Hot Plate Methods. Heat Flow Meter Method.

[10] Determination of steady-state thermal resistance and related properties - Heat flow meter apparatus, ISO 8301 Thermal insulation -

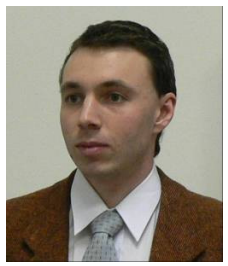

J. Zach was born in 1977, He is a doctor of Brno University of Technology, Faculty of Civil Engineering, Department of Building Materials and Components, Brno, Czech Republic. Author and co-author of 220 scientific publications. Research interests: material science, building physic, utilization of easy renewable row materials, recycling and utilization of waste for new insulation materials production, thermal protection of building structures.

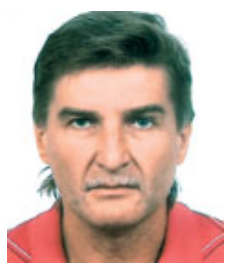

R. Hela was born in 1959 , He is a profesor of Brno University of Technology, Faculty of Civil Engineering, Department of Building Materials and Components, Brno, Czech Republic. Author and co-author of many scientific publications. The main focus of his professional activities is on concrete technology and the technology of concrete elements. He further examines issues associated with the repair of concrete structures, including the implementation of technical diagnostics and construction surveys before the start of repair work.

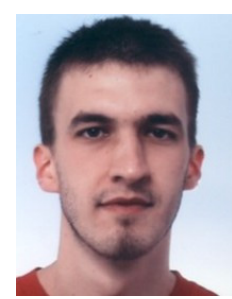

M. Sedlmajer was born in 1980, He is a doctor of Brno University of Technology, Faculty of Civil Engineering, Department of Building Materials and Components, Brno, Czech Republic. Research interests: material science, concrete technology, utilization of easy renewable row materials, recycling and utilization of waste for new insulation materials production, thermal insulation plasters.

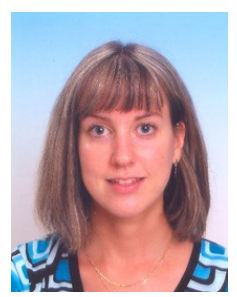

J. Hroudova was born in 1982, She is a Ph.D. student of Brno University of Technology, Faculty of Civil Engineering, Department of Building Materials and Components, Brno, Czech Republic. Research interests: material science, natural insulation materials, utilization of easy renewable row materials, recycling and utilization of waste for new insulation materials production, thermal insulation plasters. 